\title{
Urinary N-nitrosoproline excretion: a further evaluation of the nitrosamine hypothesis of gastric carcinogenesis in precancerous conditions
}

\author{
C N HALL, J S KIRKHAM, AND T C NORTHFIELD \\ From the Norman Tanner Gastroenterology Unit, St James' Hospital, Balham, London
}

SUMmARY Measurement of N-nitroso compounds in gastric juice by different methods has given conflicting results. In order to resolve this controversy, we have assessed endogenous nitrosation by the independent $\mathrm{N}$-nitrosoproline excretion test in subjects who had previously undergone gastric juice analysis by one of these methods. Ten Polya gastrectomy, 10 pernicious anaemia and nine matched control subjects were fed $380 \mathrm{mg}$ of nitrate in beetroot juice and $500 \mathrm{mg}$ proline. $\mathrm{N}$-nitrosoproline (N-Pro) synthesised intragastrically from these precursors, and quantitatively excreted by the kidneys, was measured in 24 hour urine samples (collection checked by creatinine clearance). $\mathrm{N}$-Pro excretion (mean $\pm S E M)$ was reduced $(\mathrm{p}<0 \cdot 01)$ in pernicious anaemia $(1 \cdot 1 \pm 0 \cdot 8$ $\mathrm{ng} /$ day) compared with matched control (18.0 $\pm 7 \cdot 2 \mathrm{ng} /$ day), and also tended to be lower (NS) in polya gastrectomy $(3 \cdot 2 \pm 2 \cdot 3 \mathrm{ng} /$ day $)$. Twenty four hour intragastric $\mathrm{pH}$ was monitored on a separate occasion in 23 of the 29 subjects; 13 were hypoacidic ( $\mathrm{pH}>4>50 \%$ of 24 hours) and 10 were acidic. N-Pro yields were reduced $(\mathrm{p}<0.01)$ in the hypoacidic group $(0.9 \pm 0.6 \mathrm{ng} / \mathrm{day})$ compared with the acidic group (17.9 $\pm 6 \cdot 6 \mathrm{ng} / \mathrm{day})$, and $\mathrm{N}$-Pro was negatively associated with mean intragastric $\mathrm{pH}(\mathrm{tau}=-0.53, \mathrm{p}=0 \cdot 001)$. We conclude that endogenous synthesis of this specific $\mathrm{N}$-nitroso compound is favoured by low rather than high $\mathrm{pH}$. These results are concordant with those previously reported in gastric juice from the same subjects and suggest that nitrosation is chemically rather than bacterially mediated, contrary to the nitrosamine hypothesis of gastric carcinogenesis.

The nitrosamine hypothesis of gastric carcinogenesis postulates that high intragastric $\mathrm{pH}$ in hypochlorhydria promotes the growth of bacteria which reduce dietary nitrate to nitrite and then convert dietary amines, in the presence of this nitrite, into carcinogenic $\mathrm{N}$-nitroso compounds. ${ }^{12}$ This hypothesis has been tested by the measurement of $\mathrm{N}$ nitroso compound concentrations in gastric aspirate from subjects with medically and surgically induced hypochlorhydria and in controls, but the results are conflicting. Increased concentrations have been reported as being associated with high $\mathrm{pH}^{34}$ or low

Address for correspondence: Dr T C Northfield, St Georges Hospital Medical School, Dept of Medicine II, Blackshaw Road, London SW17 0RE.

Received for publication 20 June 1986.
$\mathrm{pH}^{5}$ or as being unrelated. ${ }^{-9} \mathrm{~T}$ These discrepancies may be accounted for by differences in methodology, for a wholly satisfactory method for the determination of $\mathrm{N}$-nitroso compounds in complex biological fluids is as yet unavailable. An indirect method for the assessment of endogenous nitrosation has recently been described, ${ }^{10}$ and this obviates the need for gastric juice analysis. Instead, N-nitrosoproline excreted in the urine after the ingestion of precursors provides a quantitative measurement of nitrosation of ingested proline in gastric juice. We therefore carried out this test on Polya gastrectomy, pernicious anaemia and matched control subjects and compared the results with data on total $\mathrm{N}$-nitroso compounds in gastric juice obtained in a previous study of these same individuals. 


\section{Methods}

SUBJECTS

Ten Polya gastrectomy subjects (Visick I and II) operated on at least 15 years earlier for duodenal ulcer were compared with nine matched controls comprising healthy volunteers free of gastrointestinal disease, and with 10 pernicious anaemia subjects characterised by a previous diagnosis of macrocytic anaemia, vitamin B12 deficiency and vitamin B12 malabsorption correctable by intrinsic factor. Subjects were matched in nine triplets (plus an additional Polya gastrectomy-pernicious anaemia pairing) for race, sex, and age to the nearest decade (Table). Matching of groups was also good for height, but pernicious anaemia tended to be heavier than the other two groups (NS).

On the day of study, fasting subjects voided urine and provided a blood sample before being fed $380 \mathrm{mg}$ nitrate in beetroot juice $(200 \mathrm{ml})$ followed 30 minutes later by $500 \mathrm{mg}$ of proline in water $(100 \mathrm{ml})$. After another four hour fast (during which time smoking was not permitted), a standardised solid meal was given and then a normal daily routine was adopted. During this latter phase, subjects were merely advised to avoid potential sources of preformed $\mathrm{N}$ Pro such as cured meat products and beer. Urine was collected for 24 hours in receptacles containing $10 \mathrm{mg}$ sulphamic acid (to prevent artefactual formation of $\mathrm{N}$-Pro). Creatinine was measured in serum and fresh urine and creatinine clearance used as an approximate indicator of completeness of urine collection. Thirty millilitre aliquots of urine were stored at $-20^{\circ} \mathrm{C}$ before analysis.

$\mathrm{N}$-nitrosoproline was extracted from urine according to the method of Sen and Seaman." Twenty micrograms of $\mathrm{N}$-pipercolic acid (internal standard) was added to $15 \mathrm{ml}$ urine followed by $3 \mathrm{ml}$ of $3 \mathrm{~N}$ sulphuric acid containing $1 \%$ sulphamic acid and then the mixture placed on a Clin Elut Extube (Analytichem International, Harbour City, CA, USA) and allowed to equilibrate for five minutes. $\mathrm{N}$-nitrosamino acids were eluted with $4 \times 20 \mathrm{ml}$ of ethyl acetate, waiting two to three minutes between each elution. The eluate was dried for 30 minutes over anhydrous sodium sulphate, filtered and reduced to $2 \mathrm{ml}$ using a rotary evaporator. The

Table Matching of groups

\begin{tabular}{lccc}
\hline & Polya gastrectomy & Control & Pernicious anaemia \\
\hline Age (yr) & $65 \pm 3$ & $64 \pm 3$ & $67 \pm 3$ \\
Sex (M:F) & $7: 3$ & $6: 3$ & $7: 3$ \\
Height (cm) & $171 \pm 4$ & $170 \pm 3$ & $172 \pm 4$ \\
Weight (kg) & $66 \pm 4$ & $65 \pm 4$ & $72 \pm 5$ \\
Race & \multicolumn{3}{c}{ All caucasian } \\
\hline
\end{tabular}

resulting solution was transferred (with adequate rinsing with ethyl acetate) to a $15 \mathrm{ml}$ graduated test tube and concentrated to $0.1 \mathrm{ml}$ (avoiding evaporation to dryness) in a stream of nitrogen. Finally $1 \mathrm{ml}$ $\mathrm{BF}_{3}$-methanol reagent was added, the test tube stoppered and this mixture heated in a sand bath at $65^{\circ} \mathrm{C}$ for 30 minutes. Upon cooling to room temperature, $4 \mathrm{ml}$ water and exactly $1 \mathrm{ml}$ dichloromethane were added before agitating in a vortex mixer for two minutes. $\mathrm{N}$-nitrosamino acids were then determined by placing $6 \mu \mathrm{l}$ of the dichloromethane layer into a gas-liquid chromatograph fitted with a thermal energy analyser. Mean recovery $( \pm S E M)$ of internal standard was $65 \pm 2 \%$.

\section{STATISTICAL ANALYSIS}

Matched data were evaluated by paired Student's $t$ test and unmatched data by Wilcoxon's rank sum test. The correlation between urinary N-Pro and mean intragastric $\mathrm{pH}$ was analysed by Kendall's rank correlation coefficient ${ }^{12}$ because of the many negative yields of N-Pro and the non-normal distribution of these data.
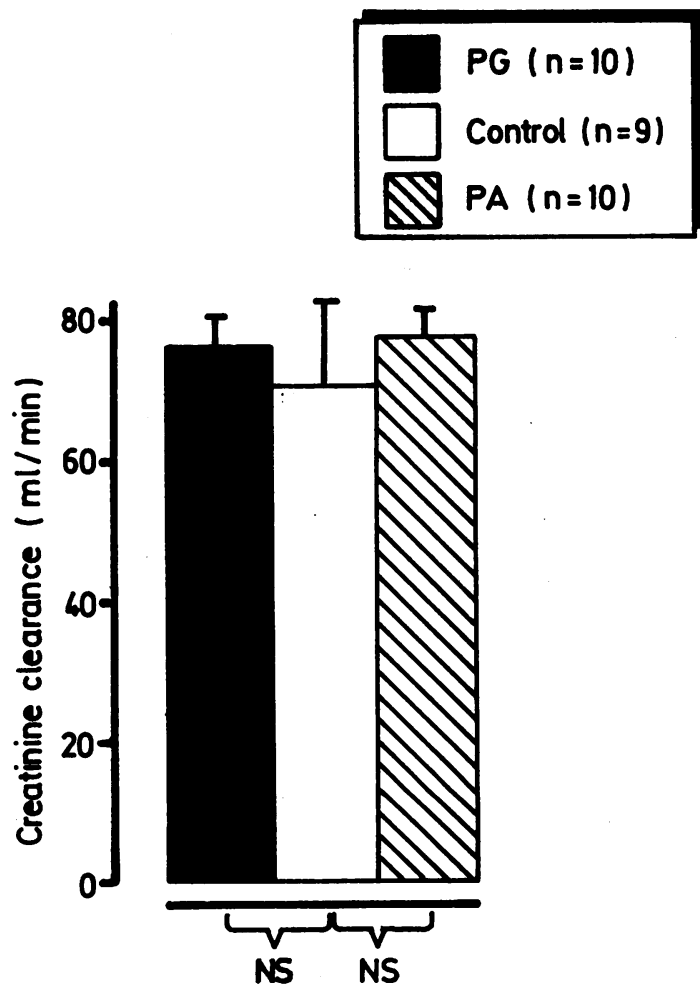

Fig. 1 Assessment of completeness of 24 hour urine collection. $(P G=$ Polya gastrectomy, $P A=$ pernicious anaemia) 


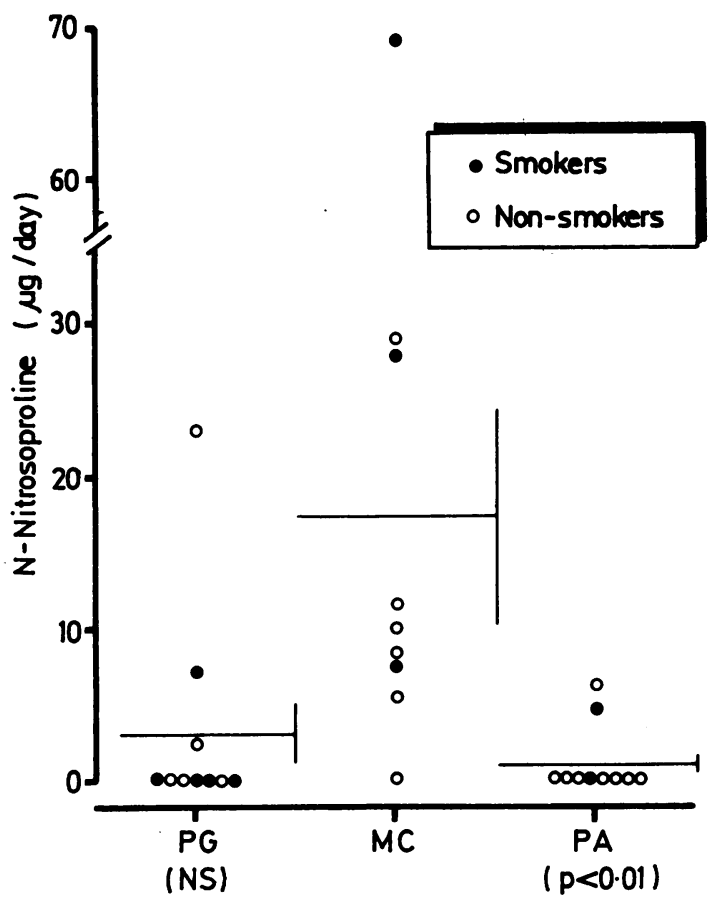

Fig. 2 Urinary yields of $N$-nitrosoproline in Polya gastrectomy $(P G)$, pernicious anaemia $(P A)$ and matched controls $(M C)$.

\section{Results}

Creatinine clearance was similar in all subjects, and there were no significant differences in clearance between groups, indicating that urine collection was very likely to have been complete (Fig. 1). Nnitrosoproline was detected in the urine of all but one matched control but in only three Polya gastrectomy and two pernicious anaemia subjects; consequently excretion (mean \pm SEM) was reduced $(p<0.01)$ in pernicious anaemia $(1 \cdot 1 \pm 0.8 \mathrm{ngm} /$ day) compared with matched controls (18.0 $\pm 7.2 \mathrm{ng} /$ day) and also tended to be lower (NS) in Polya gastrectomy (3.2 $\pm 2 \cdot 3 \mathrm{ng} /$ day) (Fig. 2).

Twenty four hour intragastric $\mathrm{pH}$ profiles were available for 23 of the 29 subjects because of their recent participation in a study of $\mathrm{N}$-nitroso compounds in gastric juice. ${ }^{5}$ Thirteen of these individuals were defined as hypoacidic $(\mathrm{pH}>4>50 \%$ of 24 hours) and 10 were acidic. Only two hypoacidic and all but one acidic individuals produced N-Pro and excretion (mean $\pm S E M)$ was reduced $(p<0.01)$ in hypoacidic $(0.9 \pm 0.6 \mathrm{ng} /$ day $)$ compared with acidic subjects (17.9 $\pm 6.6 \mathrm{ng} /$ day) (Fig. 3). N-nitrosoproline was invariably present in the urine of subjects with a mean intragastric $\mathrm{pH}<4$ and only rarely detected above this level. In addition, N-Pro yields were

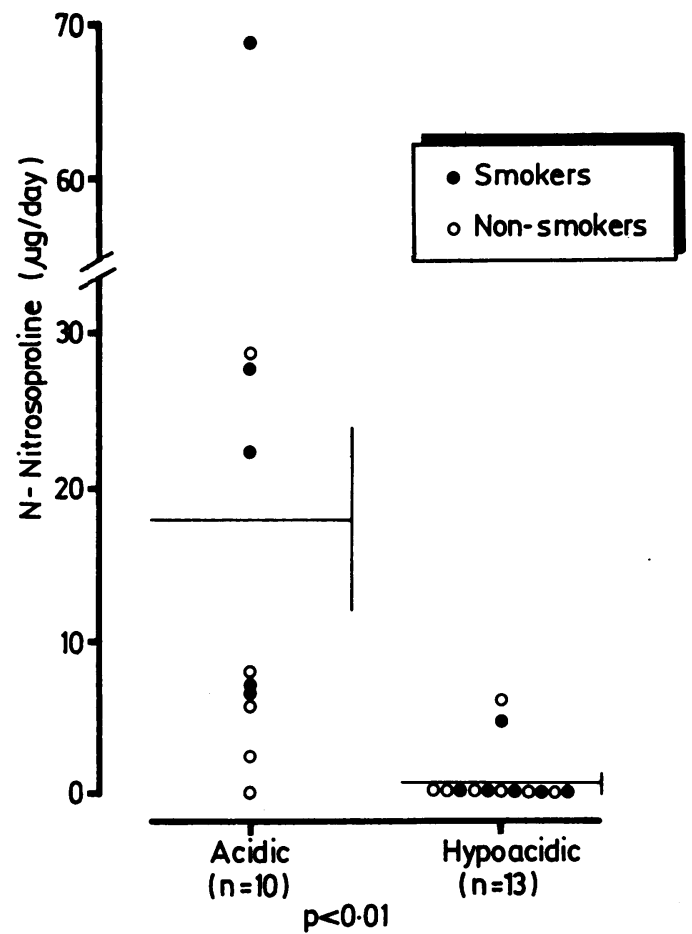

Fig. 3 Urinary yields of $N$-nitrosoproline in acidic and hypoacidic groups.

negatively associated with mean intragastric $\mathrm{pH}$ (tau $=-0.53 ; p=0.001)$ (Fig. 4).

\section{Discussion}

In order to evaluate the $\mathrm{N}$-nitroso compound hypothesis of gastric carcinogenesis, direct measurement of total $\mathrm{N}$-nitroso compound concentrations in aspirated gastric juice has been carried out, but this work is hampered by the unavailability of a wholly satisfactory method for the determination of these agents in complex biological fluids. Estimations have been done either on single samples of fasting gastric juice taken at endoscopy and stored prior to analysis $^{3489}$ or on multiple samples taken over 24 hours and analysed immediately upon retrieval. ${ }^{5-7}$ While single sample techniques may not fully represent intragastric events ${ }^{13}$ and analysis of stored material is liable to underestimate total compounds because of loss of volatile and unstable species, ${ }^{1314}$ the sole method of immediate estimation ${ }^{13}$ may not be entirely selective and may therefore be prone to overestimation. ${ }^{15}{ }^{16}$ In general, total $\mathrm{N}$-nitroso compound concentrations measured in fresh samples are approximately five to 10 -fold greater than in stored material. ${ }^{57}$ Furthermore, the reported relationship of total $\mathrm{N}$-nitroso compounds to intragastric $\mathrm{pH}$ is 


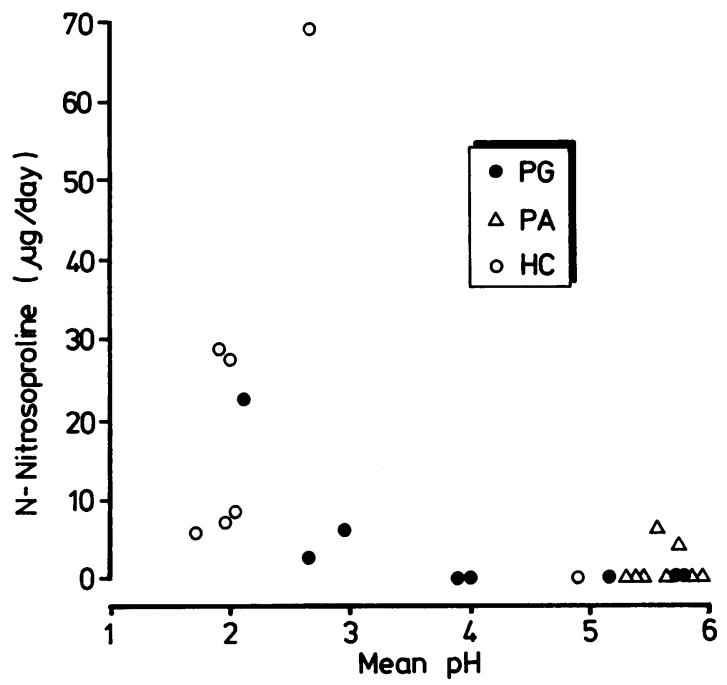

Fig. 4 Urinary N-nitrosoproline yields and gastric acidity.

inconsistent even in comparable studies using the same analytical method on stored samples ${ }^{38}$ and on fresh material. ${ }^{57}$ The $\mathrm{N}$-nitrosoproline test ${ }^{10}$ avoids the difficulties of gastric juice analysis and appears to be a valid indirect method for assessing endogenous nitrosation in man. We therefore used this test to check our recently reported data on intragastric $\mathrm{N}$-nitroso compound concentrations measured in fresh gastric samples. As cigarette smoking is reported to increase urinary $\mathrm{N}$-nitrosoproline $2 \cdot 5$-fold, ${ }^{17}$ smoking was forbidden during the first four hours of the study when intragastric concentrations of precursors were assumed to be at their highest. In any event, as can be seen from Figures 2 and 3, smokers were evenly distributed throughout the groups. The results indicate a negative association between urinary $\mathrm{N}$-nitrosoproline and mean 24 hour intragastric $\mathrm{pH}$. In the only other study of this type, Bartsch et al ${ }^{8}$ have reported a similar negative association with fasting intragastric $\mathrm{pH}$. Furthermore, the data on $\mathrm{N}$-nitrosoproline excretion correspond well with our findings on total $\mathrm{N}$-nitroso compound concentrations in the gastric juice of the same individuals. This adds credibility to the method of Bavin et $a l^{13}$ for the analysis of fresh gastric juice.

In vitro kinetics under sterile conditions show that nitrosation occurs optimally at acid $\mathrm{pH} ;{ }^{18} \mathrm{~N}$-nitrosoproline synthesis is typical and proceeds maximally at $\mathrm{pH} 2 \cdot 0-2 \cdot 5 .{ }^{19}$ In addition, experiments with both gastric juice ${ }^{20}$ and saliva ${ }^{21}$ indicate that dissolution of precursors in these media results in the same characteristics of nitrosation as occurs in water. The $\mathrm{N}$-nitroso compound hypothesis of gastric carcinogenesis, on the other hand postulates that in vivo bacterial mechanisms enhance nitrosation at high intragastric $\mathrm{pH}$. Our results are consistent in showing that both total $\mathrm{N}$-nitroso compounds in gastric juice and $\mathrm{N}$-nitrosoproline in urine are reduced in hypoacidic subjects, and this suggests that chemical mechanisms of nitrosation predominate in vivo in man contrary to the $\mathrm{N}$-nitroso compound hypothesis.

We are grateful to Dr B C Challis, Dr C L Walters and Mr P L R Smith for advice and technical assistance with the measurement of urinary $\mathrm{N}$-nitrosoproline.

\section{References}

1 Correa P, Haenszel W, Cuello C, Tannenbaum S, Archer M. A model for gastric cancer epidemiology Lancet 1975; 2: 58-60.

2 Ruddell WSJ, Bone ES, Hill MJ, Walters CL. Pathogenesis of gastric cancer in pernicious anaemia. Lancet 1978; 1: 521-3.

3 Reed PI, Smith PLR, Haines K, House FR, Walters CL. Gastric juice N-nitrosamines in health and gastroduodenal disease. Lancet 1981; ii: 550-2.

4 Stockbrugger RW, Cotton PB, Eugenides N, Bartholomew BA, Hill MJ, Walters CL. Intragastric nitrites, nitrosamines and bacterial overgrowth during cimetidine treatment. Gut 1982; 23: 1048-54.

5 Hall CN, Darkin D, Brimblecombe R, Hill MJ, Kirkham JS, Northfield TC. An evaluation of the nitrosamine hypothesis of gastric carcinogenesis in precancerous conditions. Gut 1986; 27 : 491-8.

6 Milton-Thompson GJ, Lightfoot NF, Ahmet Z, et al. Intragastric acidity, bacteria, nitrite and $\mathrm{N}$-nitroso compounds before, during and after cimetidine treatment. Lancet 1982; i: 1091-5.

7 Keighley MRB, Youngs D, Poxon V, et al. Intragastric $\mathrm{N}$-nitrosation is unlikely to be responsible for gastric carcinoma developing after operations for duodenal ulcer. Gut 1984; 25 : 238-45.

8 Bartsch $\mathrm{H}$, Ohshima $\mathrm{H}$, Munoz $\mathrm{O}$, et al. In-vivo nitrosation, precancerous lesions and cancers of the gastrointestinal tract. On-going studies and preliminary results. In: O'Neill IK, Von Borstel RC, Miller CT, Long J, Bartsch $\mathrm{H}$, eds. $N$-nitroso compounds: occurrence, biological effects and relevance to human cancer. IARC Scientific Publications No. 57. Lyon: IARC, 1984: 955-62.

9 Sturniolo G, Carditello A, Bonavita G, Bartolotta M, Saitta E. Risk factors for development of primary cancer in the gastric stump. Acta Chir Scand 1983; 149: 591-6.

10 Ohshima $\mathrm{H}$, Bartsch $\mathrm{H}$. Quantitative estimation of endogenous nitrosation in human by monitoring $\mathrm{N}$ nitrosoproline excreted in the urine Cancer Res 1981; 41: 3658-62.

11 Sen NP, Seaman S. On-line combination of high performance liquid chromatography and total $\mathrm{N}$-nitroso determination apparatus for the determination of $\mathrm{N}$ nitrosamides and other $\mathrm{N}$-nitroso compounds and some recent data on the levels of $\mathrm{N}$-nitrosoproline in foods 
and beverages. In: O'Neill IK, Von Borstel RC, Miller $\mathrm{CT}$, Long J, Bartsch $\mathrm{H}$, eds. $N$-nitroso compounds: bccurrence, biological effects and relevance to human cancer. IARC Scientific Publications No. 57. Lyon: IARC, 1984; 137-43.

12 Kendall MG. Rank correlation methods. London: Griffin, 1970

13 Bavin PMG, Darkin DW, Viney NJ. Total Nitroso compounds in gastric juice. In: Bartsch $\mathrm{H}$, O'Neill IK, Castegnaro M, Okada $\mathrm{M}$, eds. In: $N$-nitroso compounds: occurrence and biological effects. IARC Scientific Publication No. 41. Lyon: IARC, 1982: 33743.

14 Ruddell WSJ, Walters CL. Nitrite and N-nitroso compounds in gastric juice. Lancet. 1980; i: 1187.

15 Reed PI, Haines K, Smith PLR, Walters CL, House FR. Intragastric acidity, bacteria, nitrite and $\mathrm{N}$-nitroso compounds before, during and after cimetidine treatment. Lancet 1982; ii: 39.

16 Walters CL, Smith PLR, Reed PI. Pitfalls to avoid in determining $\mathrm{N}$-nitroso compounds as a group. In: O'Neill IK, Von Borstel RC, Miller CT, Long J, Bartsch
$\mathrm{H}$, eds. $N$-nitroso compounds: occurrence, biological effects and relevance to human cancers. IARC Scientific Publication No. 57. Lyon: IARC, 1984: 113-20.

17 Ladd KF, Archer MC, Newmark HL. Increased endogenous nitrosation in smokers. In: O'Neill IK, Von Borstel RC, Miller CT, Long J, Bartsch $\mathrm{H}$, eds. $\mathrm{N}$ nitroso compounds: occurrence, biological effects and relevance to human cancers. IARC Scientific Publication No. 57. Lyon: IARC, 1984: 811-7.

18 Douglass ML, Kabacoff BL, Anderson GA, Cheng MC. The chemistry of nitrosamine formation, inhibition and destruction. J Soc Cosmet Chem 1978; 29: 581-606.

19 Mirvish SS, Sams J, Fran TY, Tannenbaum SR. Kinetics of nitrosation of the amino acids proline, hydroxyproline and sarcosine. J Natl Cancer Inst 1973; 51: 1833-9.

20 Lane RP, Bailey ME. The effect of $\mathrm{pH}$ on dimethylnitrosamine formation in human gastric juice. Food Cosmet Toxicol 1973; 11: 851-4.

21 Tannenbaum SR, Archer MC, Wishnok JS, Bishop WW. Nitrosamine formation in human saliva. $J$ Natl Cancer Inst 1978; 60: 251-3. 